Vittalle - Revista de Ciências da Saúde 29 n. 2 (2017) 57-78
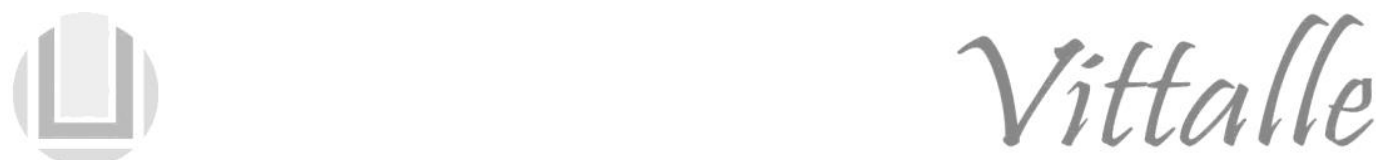

\title{
Exercício físico e neuroplasticidade hipocampal: Revisão de literatura
}

\author{
Cristine de Paula Nascimento-Castro ${ }^{a^{*}}$, Joana Gil-Mohapel ${ }^{\mathrm{b}}$, Patricia de Souza \\ Brocardo ${ }^{\mathrm{a}, \mathrm{c}^{*}}$
}

aPrograma de Pós-Graduação em Neurociências, Centro de Ciências Biológicas, Laboratório de Neuroplasticidade, Universidade Federal de Santa Catarina, Florianópolis, Santa Catarina, Brasil.

bivision of Medical Sciences and UBC Island Medical Program, University of Victoria, Victoria, BC, Canadá

${ }^{\mathrm{c}}$ Departamento de Ciências Morfológicas, Universidade Federal de Santa Catarina, Florianópolis, Santa Catarina, Brasil.

\section{Histórico do Artigo \\ Palavras-chave \\ Exercício físico Hipocampo giro denteado neurogênese plasticidade}

Recebido em:15/09/2017

Aceito em: 12/11/2017

Keywords: Physical exercise hippocampus dentate gyrus neurogenesis plasticity

\section{RESUMO}

O exercício físico (EF) é capaz de melhorar a saúde física e muitos aspectos da função cerebral. Em humanos, vários estudos evidenciam a importância do EF para a saúde geral e para a função cognitiva. Diversos trabalhos experimentais têm avaliado as alterações celulares, moleculares e funcionais provocadas pelo exercício físico voluntário (EFV) no Sistema Nervoso Central (SNC) de roedores. Dentre os diferentes aspectos da função cerebral, o processo de plasticidade estrutural e sináptica do hipocampo recebe grande importância devido à alta plasticidade e reatividade desta estrutura ao EF. O hipocampo está localizado no lobo temporal do encéfalo de mamíferos e está envolvido de forma crítica no processo de aprendizagem e memória e na modulação da cognição e transtornos de humor em diferentes doenças neurodegenerativas. Além disso, como estrutura integrante do sistema límbico, o hipocampo está relacionado com o controle das emoções, portanto disfunções, nesta estrutura, estão ligadas a alterações comportamentais como a depressão. Dentre os diferentes moduladores da plasticidade hipocampal, o EF destaca-se pelo seu efeito neurogênico bem como a sua capacidade de remodelar sinapses e modificar propriedades neuronais. Sendo assim, o presente trabalho visa reunir diversos trabalhos experimentais e clínicos que evidenciam os efeitos positivos induzidos pelo EFV na plasticidade estrutural e funcional do hipocampo.

Physical exercise and hippocampal neuronal plasticity: literature review

\section{ABSTRACT}

Physical exercise is able to improve physical health and brain function. In humans, various studies evidence the importance of physical exercise for overall health and cognitive function. Several experimental studies have evaluated the cellular, molecular and functional alterations caused by voluntary physical exercise in the central nervous system of rodents. Hippocampal structural and synaptic plasticity is greatly affected by physical exercise. The hippocampus is a structure located in the temporal lobe of the mammalian brain and is critically involved in the process of learning and memory and in the modulation of cognitive and affective disorders in different neurodegenerative diseases. In addition, as a structure of the limbic system, the hippocampus is related to the control of emotions and, therefore, dysfunctions in this structure are linked to behavioral alterations such as depression. Voluntary physical exercise is capable of inducing a series of changes in hippocampal plasticity either through the stimulation of the adult neurogenesis process (structural plasticity) or remodeling synapses and causing functional alterations in the neurons (synaptic plasticity), consequently modulating hippocampal function. Thus, the present work aims to bring together several experimental and clinical studies that demonstrate the positive effects of voluntary physical exercise on the structural and functional plasticity of the hippocampus.

\footnotetext{
*Autor Correspondente: patricia.brocardo@ufsc.br (P. S. Brocardo)
} 


\section{Introdução}

Exercício físico (EF) é um termo geral usado para descrever uma atividade física planejada, estruturada e repetitiva, com o propósito de condicionar qualquer parte do corpo(1). Além dos seus benefícios para a saúde física, diversos trabalhos comprovam os efeitos positivos do exercício sobre o Sistema Nervoso Central (SNC) em roedores (2-4) e em humanos $(5,6)$.

Os modelos animais, principalmente roedores, são considerados ferramentas importantes para o estudo dos mecanismos através dos quais o EF exerce seus efeitos sobre as funções cerebrais. Estes estudos experimentais abrangem diversos protocolos, incluindo diferentes intensidades e frequências de exercício, podendo ser aplicados em período de curta ou longa duração (7). O exercício físico voluntário (EFV), foco desta revisão, é o modelo de atividade física mais utilizado nos estudos experimentais $(2,4,8)$.

A plasticidade neuronal é a capacidade de modificação e adaptação do SNC frente a diversas experiências e estímulos. A plasticidade pode ocorrer através do nascimento de novos neurônios (neurogênese adulta), remodelamento das sinapses (9) e alterações funcionais nas células neuronais $(2,10)$. Ogiro denteado (GD) hipocampal é uma das duas regiões conhecidas do encéfalo em que ocorre a neurogênese adulta, ou seja, o contínuo nascimento de novos neurônios durante toda a vida. Este processo pode ser influenciado negativamente por diversos fatores como envelhecimento (11), estresse (12) e inflamação (13); e pode ser influenciado positivamente pelo $\mathrm{EF}(2,10,14,15)$. Além desta alteração morfológica, diferentes sistemas moleculares e vias de sinalização celular envolvidos na função sináptica e funcionamento do SNC, incluindo $o$ hipocampo, podem ser alterados positivamente pelo EF (16-18).

Dada a relevância do EF sobre as diferentes formas de plasticidade hipocampal, este trabalho tem como finalidade reunir as diversas contribuições de trabalhos experimentais e clínicos que sugerem que o EF seja um fator crítico para o aumento da plasticidade e, consequentemente, para a melhora da função hipocampal.

\section{Material e métodos}

O presente estudo trata de uma revisão bibliográfica relacionada aos efeitos do EFV sobre a função hipocampal (plasticidade estrutural e sináptica). Para a localização dos artigos científicos, foi criada uma estratégia de busca na base de dados PubMede ScienceDirect com os seguintes unitermos: neuronal plasticity, exercise and neurogenesis. Foram selecionados artigos experimentais que abordavam alterações celulares e moleculares bem como estudos clínicos que avaliaram as alterações estruturais e funcionais presentes no hipocampo após a prática do EFV.

Foram usados, como critério de exclusão, trabalhos que utilizavam exercício físico forçado ou aqueles em que o exercício era associado a outras atividades (ambiente enriquecido), trabalhos que avaliavam algum tipo de plasticidade em outras estruturas não associadas ao hipocampo e aqueles que utilizavam animais geneticamente modificados. Foram considerados os trabalhos publicados em inglês, entre 1999 e 2017.

\section{Resultados e Discussão}

\section{Exercício Físico e Função Cerebral}

O EF é capaz de exercer várias alterações positivas no SNC através de diferentes mecanismos; muito do que se conhece sobre estes efeitos do EF foram obtidos com o uso de modelos animais. Os roedores são considerados ferramentas importantes para o estudo dos mecanismos através dos quais o EF exerce seus efeitos sobre as funções 
cerebrais. Estes estudos experimentais abrangem diversos protocolos, incluindo diferentes intensidades e frequências de exercício, podendo ser aplicados em período de curta ou longa duração (7). O tipo de atividade ou tarefa, e a forma como esta é realizada exerce diferentes efeitos sobre o encéfalo (19). Os principais tipos são: exercício voluntário $(2,4,8,20)$, ambientes enriquecidos $(14,21,22)$, exercícios forçados como natação $(23,24)$ e esteira $(25,26)$. No EFV, que será o foco desta revisão, os animais executam a atividade com tempo, frequência e intensidade definidos por eles mesmos. Por exemplo, ao correr em uma roda de corrida dentro do seu ambiente, podemos observar que alguns roedores correm vários quilômetros por dia, enquanto outros pouco se envolvem na atividade $(7,27)$.Em animais, a roda de corrida voluntária é a forma de EFV mais utilizada e, nesta revisão, todos os trabalhos com roedores utilizaram a roda de corrida como forma de EFV.

Muitos dos estudos que utilizam o EFV avaliam a plasticidade neural em áreas relacionadas à aprendizagem motora e memória. $\mathrm{O}$ aumento do fator neurotrófico derivado do encéfalo (BDNF), o aumento da expressao de genes envolvidos no tráfego sináptico (por exemplo, STY1, STY11) e das proteínas relacionadas à formação de vesículas sinápticas e exocitose (por exemplo, SYN1 e SNAP25) associado à plasticidade sináptica, à excitabilidade celular e à ativação de cascatas proteíno-quinases ativadas por mitógenos (MAP quinases) foram observadas no hipocampo após o $\operatorname{EFV}(3,16,26,28-30)$. Além disso, o EFV mostrou ser capaz de aumentar a proliferação e diferenciação celular no GD hipocampal e melhorar a transmissão sináptica (2), além de alterar a atividade de neurotransmissores como a serotonina (31) e a dopamina (32)nos encéfalos de roedores.

O EF é conhecido por aumentar a cognição em animais experimentais e em humanos em diferentes grupos etários. OEF tem sido associado à melhora da função cognitiva e memória em humanos $(5,33,34)$ e roedores $(15,35-39)$. Além disso, efeitos antidepressivos e ansiolíticos do EFV já foram relatados em animais (40-43) e humanos (44-48).

\section{Neuroplasticidade Estrutural e Funcional no Hipocampo Adulto}

Durante muito tempo, acreditou-se que, após seu desenvolvimento, o SNC tornava-se uma estrutura rígida, que não poderia ser modificada, e que lesões neste seriam permanentes, pois suas células não poderiam ser reconstituídas ou reorganizadas. Hoje, sabemos da capacidade de modificação e adaptação do SNC em função de suas experiências ou como tentativa de regeneração. Esta capacidade de adaptabilidade do encéfalo, de modificar ascircuitarias neurais existentes através da adição de novos neurônios ou pelo remodelamento das sinapses já existentes $(9,49)$ é denominada neuroplasticidade.Existem dois tipos de neuroplasticidade: a Estrutural e a Funcional ou Sináptica. A plasticida de estrutural é caracterizada pelo processo de neurogênese adulta e por alterações numéricas e morfológicas dos espinhos dendríticos; e a plasticidade sináptica pelo fortalecimento, enfraquecimento e/ou remodelamento das sinapses existentes $(50,51)$.

O hipocampo está localizado no lobo temporal de cada hemisfério encefálico, e apresenta tanto plasticidade estrutural quanto plasticidade sináptica. Com base na morfologia celular e nas projeções de suas fibras, o hipocampo é subdividido em regiões CA (do latim Cornu Anmonis; organizada em subregiões denominadas CA1, CA2, CA3, e CA4) e no GD (Figura 1 painel superior). O GD é uma estrutura trilaminar dividida em camada molecular (ocupada basicamente pelos dendritos das células granulares em cesto e polimórficas), a camada granular (camada principal de células que tem corpos celulares pequenos e esféricos) em camada polimórfica (também chamada de hilo, onde se encontram as células musgosas) (52). 


\section{Exercício Físico aumenta a Plasticidade Estrutural no Hipocampo Adulto}

A plasticidade estrutural do hipocampo ocorre através do processo de neurogênese hipocampal adulta e é restrita a algumas regiões encefálicas, incluindo o GD (Figura 1). O processo da neurogênese hipocampal adulta é composto por quatro fases: (1) proliferação; (2) migração; (3) diferenciação e (4) maturação celular. Azona subgranular (ZSG)do GD é o local onde ocorre a proliferação e a diferenciação celular. Desta zona, os neurônios imaturos migram para a camada granular onde passam pelo processo de maturação, dando origem às células granulares propriamente ditas, onde se integram à circuitaria neuronal local (53-57).

O primeiro precursor celular na ZSG é um tipo de astrócito radial (58), que expressa a proteína glial fibrilar ácida (GFAP; do inglês, glial fibrillary acidic protein), nestina e outros marcadores endógenos de proliferação celular (como, por exemplo, Ki-67 e PCNA; do inglês, proliferating cell nuclear antigen) (55). As células do tipo II expressam apenas nestina, sendo negativas para GFAP (54). Essas células são mitoticamente ativas e atuam como células progenitoras neurais amplificadoras por alguns dias, quando param suas divisões e começam a expressar marcadores de neurônios imaturos(59). É durante essa etapa de transição que mais de $60 \%$ das novas células morrem por apoptose e são fagocitadas por células microgliais (60). Os neuroblastos pós-mitóticos que sobrevivem já não expressam nestina, mas começam a expressar a proteína associada a microtúbulos, a doublecortina (DCX). A diferenciação neuronal pós-mitótica é caracterizada pela expressão transitória de DCX, da proteína ligante de cálcio Calretinina, da Proteína Nuclear Neuronal (NeuN) e da Calbindina (59) (Figura 1).

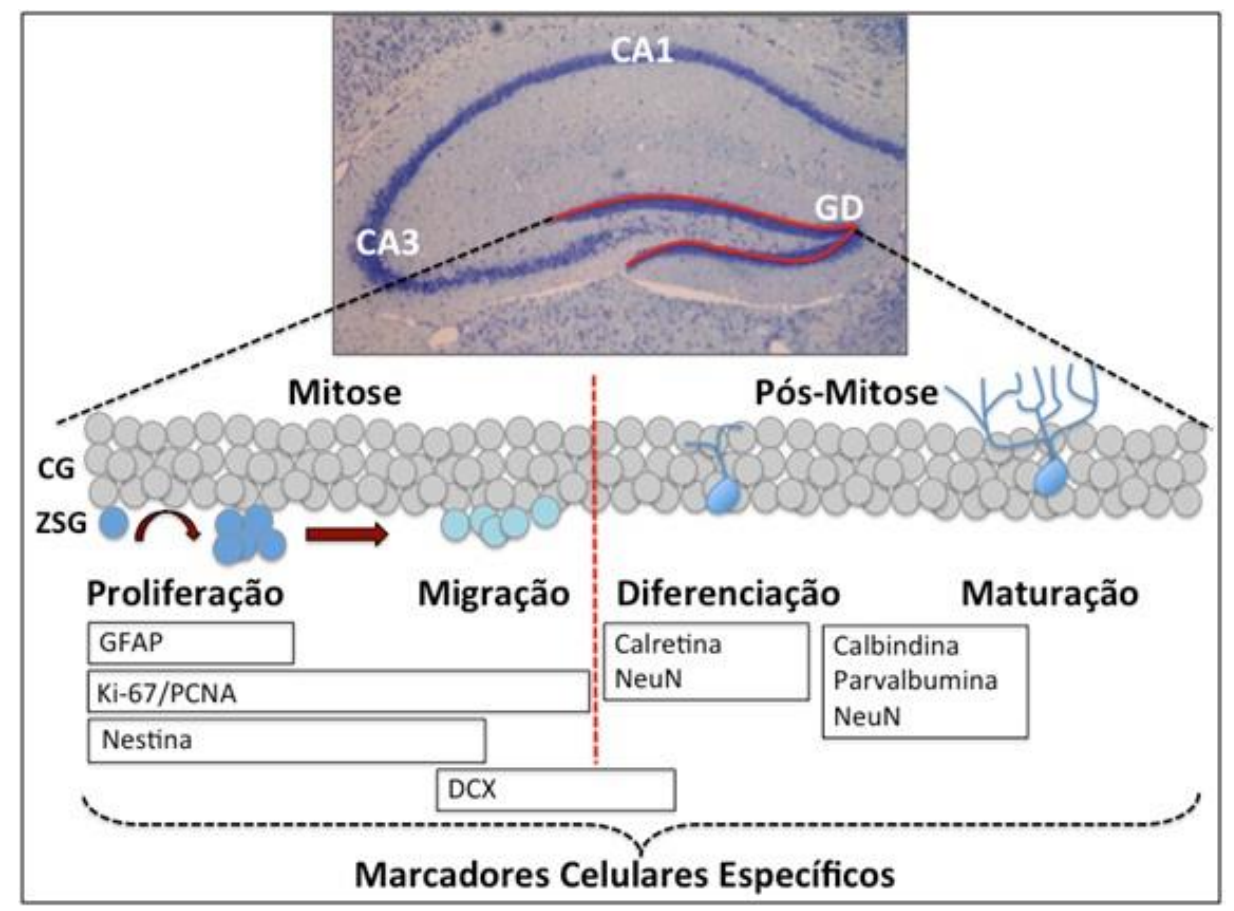

Figura 1- Neurogênese Hipocampal Adulta- Painel superior: vista frontal do encéfalo de um roedor mostrando as regiões do hipocampo, com destaque para o GD, local de neurogênese hipocampal. O hipocampo forma uma circuitaria trissináptica, que conecta o córtex entorrinal ao hipocampo (GD, CA3 e CA1). Células proliferativas na SGZ migram e se diferenciam em neurônios maduros. Painel inferior: resumo dos principais marcadores de neuronais expressos durante a neurogênese pós-natal. Abreviações: GD- Giro Denteado; CA3 - Área CA3 do corno de Ammon; CA1- Área CA1 do corno de Ammon; ZSGZona Subgranular; CG- camada granular. Fonte: do autor. 
O marcador exógeno mais utilizado para estudar a neurogênese adulta em estudos préclínicos é o 5-bromo-2'-deoxiuridina (BrdU), que é incorporado nas células mitóticas durante a fase de síntese (dentro de 2 horas após a injeção), sendo assim transmitido para as células filhas. Assim, o BrdU pode ser usado como um marcador de proliferação celular ou de sobrevivência destas novas células, dependendo do intervalo de tempo entre a administração do composto e a perfusão dos animais (61). Outra estratégia para identificar células em proliferação ou células diferenciadas é o uso de proteínas endógenas que somente se expressam durante a fase mitótica ativa celular (62) ou quando o fenótipo celular (neuronal ou glial) já está definido (63).

A neurogênese hipocampal adulta e cada uma das suas fases é muito bem regulada (64). Além da regulação parcial por fatores genéticos, a geração de novos neurônios no cérebro adulto é também regulada por fatores fisiológicos, patológicos e comportamentais. Por exemplo, o estresse (12), a inflamação (13), e o envelhecimento (11) regulam negativamente a neurogênese adulta. Enquanto fármacos antidepressivos $(65,66)$, fatores de crescimento (substâncias que modulam sinalização, diferenciação e sobrevivência celular) (67), ambiente enriquecido (68) e o EF (2, 14) regulam positivamente a capacidade neurogênica do cérebro adulto.

Embora cerca de 700 novos neurônios sejam gerados todos os dias no GD humano(69), seu exato papel ainda está em debate. Alguns estudos suportam a funcionalidade destes novos neurônios em processos de aprendizagem e memória (7072). Por exemplo, sabe-se que os novos neurônios do GD desempenham um papel importante no padrão de separação, um mecanismo de memória que nos permite diferenciar representações similares codificadas por circuitos hipocampais $(73,74)$. Em humanos, a separação de padrões pode ser acessada pela combinação do uso de ressonância magnética funcional e de testes específicos de memória (75). Prejuízos nestes testes associados com a separação de padrões em humanos podem ser um indicador precoce de disfunção do GD e um possível sinal inicial de déficits cognitivos associados a doenças neurodegenerativas. Alterações nestes testes também estão associadas com mudanças na atividade do córtex entorrinal, a principal entrada de informações para o GD (76), provavelmente afetando a sobrevivência dos novos neurônios hipocampais (77).

As células neuronais granulares são o tipo de neurônio glutamatérgico excitatório mais prevalente no GD, e a sua produção em adultos é regulada pelo EF através da regulação positiva dos níveis do $\operatorname{BDNF}(64,78)$. Estes neurônios são ativados preferencialmente durante a execução de comportamentos dependentes do hipocampo $(64,79,80)$. Por exemplo, um estudo demonstrou que a irradiação, processo conhecido por inibir a neurogênese, elimina os efeitos positivos do EF em aumentar a função hipocampal, especialmente a memória espacial (15).

Os efeitos benéficos do EFV (roda de corrida) na neurogênese hipocampal adulta foram primeiramente reportados por Van Praag e colaboradores (1999) que mostraram que a exposição à roda de corrida é capaz de aumentar a proliferação celular e neurogênese no GD de camundongos adultos $(2,14)$. Depois deste artigo, vários outros estudos demonstraram que o EFV é um indutor robusto da neurogênese no GD em animais jovens, adultos e idosos (37, 39, 81-88).

Diversos estudos têm revelado que o EFV é capaz de exercer seus efeitos em diferentes estágios da neurogênese hipocampal adulta. A fim de facilitar abordagens dos diferentes estudos envolvendo $\mathrm{EFV}$, os trabalhos foram agrupados em períodos curtos (12 horas - 28 dias) e longos (32 dias -8 meses) de EFV. A grande maioria dos trabalhos tem demonstrado que a exposição à roda de corrida por períodos curtos (7-28 
dias) são capazes de promover o processo de proliferação celular $(4,8,10,14,82,85$, 89-93) e diferenciação neuronal $(4,82,91-93)$ no GD de ratos e camundongos adultos. Porém, poucos estudos têm avaliado os efeitos do EFV no período curto de 3 dias na proliferação celular e diferenciação neuronal $(82,83,93)$. Estes estudos demonstraram que mesmo este curto período de tempo é capaz de aumentar a proliferação celular (83, 93 ) e a diferenciação neuronal $(82,83,93)$ no GD de camundongos adultos. Apesar da grande maioria dos trabalhos demonstrarem que alterações na diferenciação neuronal provocadas pelo EF exigem dias a semanas, Kerr e Swain (94) demonstraram que apenas 12 horas de exposição à roda de corrida voluntária é suficiente para aumentar o número de neuroblastos em ratos. Vale ressaltar que neste trabalho a mensuração da diferenciação neuronal foi realizada por imunodetecção de proteínas (Western Blot) para a DCX, diferentemente da totalidade dos demais trabalhos abordados nesta revisão que avaliam os diferentes processos da neurogênese adulta através da técnica de imunohistoquímica. Estes resultados indicam que novos neurônios imaturos são gerados rapidamente e que esta alteração permanece constante durante alguns dias após o início do exercício. Possivelmente, este efeito rápido do EF sobre a diferenciação neuronal esteja relacionado à melhora da angiogênese, resultante do aumento da demanda metabólica provocada pelo EF. O aumento da angiogênese poderia ser um fator crítico para a sobrevivência de neurônios imaturos (94). Além disso, Kronenberg e colaboradores (2006) demonstraram que o EFV foi capaz de aumentar o número de células proliferativas após o período de 3 e 10 dias e este número retornou a níveis basais após um período mais prolongado (32 dias). Estudos têm demonstrado que períodos curtos de EFV (10 dias) são capazes de reverter o declínio na neurogênese relacionado com a idade, como demonstrado pelo aumento da proliferação $(83,85)$ e diferenciação neuronal (83) em camundongos idosos. Estes resultados demonstram a importância da intervenção do EF em qualquer faixa etária (Tabela 1).

Tabela 1 - Efeitos de períodos curtos de EFV na Neuroplasticidade Estrutural Hipocampal

\begin{tabular}{|c|c|c|c|c|c|}
\hline Linhagem & Idade/gênero & Duração & Marcadores & Efeitos & Referências \\
\hline $\begin{array}{l}\text { Camundongo } \\
\text { C57BL/6 }\end{array}$ & $\begin{array}{l}3 \text { meses/ } \\
\text { Fêmeas }\end{array}$ & 12 dias & BrdU & †proliferação & $\begin{array}{l}(14) \\
(8)\end{array}$ \\
\hline $\begin{array}{l}\text { Camundongo } \\
\text { C57BL/6 }\end{array}$ & $\begin{array}{l}74 \text { dias/ } \\
\text { Machos }\end{array}$ & $\begin{array}{c}3 \text { e } 10 \\
\text { dias }\end{array}$ & $\begin{array}{c}\text { BrdU e Ki-67 } \\
\text { DCX/ } \\
\text { Calretina }\end{array}$ & $\begin{array}{c}\text { 个proliferação } \\
\uparrow \text { diferenciação }\end{array}$ & (83) \\
\hline $\begin{array}{l}\text { Camundongo } \\
\text { C57BL/6 }\end{array}$ & $\begin{array}{l}12 \text { e } 24 \\
\text { meses/ } \\
\text { Machos }\end{array}$ & 10 dias & $\begin{array}{c}\text { BrdU } \\
\text { DCX/ } \\
\text { Calretina }\end{array}$ & $\begin{array}{c}\text { †proliferação } \\
\uparrow \text { diferenciação }\end{array}$ & $(83)$ \\
\hline $\begin{array}{l}\text { Camundongo } \\
\text { C57BL/6 }\end{array}$ & $\begin{array}{l}2 \text { meses/ } \\
\text { Machos }\end{array}$ & 12 dias & $\begin{array}{c}\text { BrdU e PCNA } \\
\text { DCX }\end{array}$ & $\begin{array}{c}\text { } \text { proliferação } \\
\text { } \text { diferenciação }\end{array}$ & $(91)$ \\
\hline $\begin{array}{c}\text { Camundongo } \\
\text { C57BL/6 }\end{array}$ & $\begin{array}{l}2 \text { meses / } \\
\text { Fêmeas }\end{array}$ & 28 dias & BrdU/NeuN & $\uparrow$ neurogênese & (141) \\
\hline $\begin{array}{l}\text { Camundongo } \\
\text { C57BL/6 }\end{array}$ & $\begin{array}{c}2 \text { meses/ } \\
\text { Fêmeaa }\end{array}$ & $\begin{array}{c}1,3 \text { e } 7 \\
\text { dias }\end{array}$ & $\begin{array}{c}\text { BrdU, IdU e } \\
\text { CldU } \\
\text { DCX/calretina }\end{array}$ & $\begin{array}{c}\uparrow \text { proliferação } \\
\text { (7d) } \\
\uparrow \text { diferenciação } \\
\text { (3 e 7d) }\end{array}$ & $(82)$ \\
\hline $\begin{array}{l}\text { Camundongo } \\
\text { C57BL/6 }\end{array}$ & $\begin{array}{c}\text { 17-18 meses/ } \\
\text { Fêmeas }\end{array}$ & 11 dias & BrdU & ^proliferação & $(85)$ \\
\hline $\begin{array}{l}\text { Camundongo } \\
\text { C57BL/6 }\end{array}$ & $\begin{array}{c}9 \text { semanas/ } \\
\text { Machos }\end{array}$ & 14 dias & $\begin{array}{c}\text { Ki-67 } \\
\text { BrdU } \\
\text { (sobrevivência) }\end{array}$ & $\begin{array}{c}\text { ^proliferação e } \\
\text { sobrevivência }\end{array}$ & (4) \\
\hline
\end{tabular}




\begin{tabular}{|c|c|c|c|c|c|}
\hline $\begin{array}{c}\text { Camundongo } \\
\text { C57BL/6 }\end{array}$ & $\begin{array}{l}2 \text { meses/ } \\
\text { Machos }\end{array}$ & $\begin{array}{c}3 \\
\text { semanas } \\
\text { (protocolo } \\
\text { de } \\
\text { exercício: } \\
\text { 3h/dia ou } \\
\text { 24h/dia) }\end{array}$ & $\begin{array}{c}\text { pH3 } \\
\text { (proliferação) } \\
\text { BrdU } \\
\text { (sobrevivência) } \\
\text { DCX }\end{array}$ & $\begin{array}{c}\text { ¡proliferação e } \\
\text { sobrevivência } \\
\uparrow \text { diferenciação }\end{array}$ & (142) \\
\hline $\begin{array}{c}\text { Rato } \\
\text { Sprague- } \\
\text { dawley }\end{array}$ & $\begin{array}{c}\text { 200-250gr } \\
\text { Machos }\end{array}$ & $\begin{array}{c}2 \text { ou } 3 \\
\text { semanas }\end{array}$ & BrdU e Ki-67 & †proliferação & (89) \\
\hline $\begin{array}{c}\text { Rato } \\
\text { Sprague- } \\
\text { dawley }\end{array}$ & $\begin{array}{c}\text { 45-50 dias } \\
\text { Machos }\end{array}$ & 2 semanas & BrdU & 个proliferação & $(90)$ \\
\hline $\begin{array}{c}\text { Rato } \\
\text { Sprague- } \\
\text { dawley }\end{array}$ & $\begin{array}{c}10-12 \\
\text { semanas } \\
\text { Machos }\end{array}$ & 10 dias & $\begin{array}{c}\text { BrdU e Ki-67 } \\
\text { BrdU/NeuN }\end{array}$ & 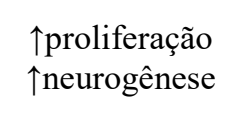 & $(10)$ \\
\hline $\begin{array}{c}\text { Rato } \\
\text { Sprague- } \\
\text { dawley }\end{array}$ & $\begin{array}{c}250 \mathrm{gr} \pm 20 \\
\text { Machos }\end{array}$ & 14 dias & $\begin{array}{l}\text { BrdU } \\
\text { DCX }\end{array}$ & $\begin{array}{c}\text { †proliferação } \\
\uparrow \text { diferenciação }\end{array}$ & $(92)$ \\
\hline $\begin{array}{l}\text { Rato } \\
\text { Long } \\
\text { Evans }\end{array}$ & $\begin{array}{c}\text { 175-200gr } \\
\text { Machos }\end{array}$ & $\begin{array}{l}12,24 \text { e } \\
48 \text { horas } \\
4 \text { e } 6 \text { dias }\end{array}$ & DCX & diferenciação & (94) \\
\hline $\begin{array}{c}\text { Rato } \\
\text { Sprague- } \\
\text { dawley }\end{array}$ & $\begin{array}{l}2 \text { meses } \\
\text { Machos }\end{array}$ & $\begin{array}{l}3,7,14 \\
28 \text { dias }\end{array}$ & $\begin{array}{c}\text { Ki-67 } \\
\text { NeuroD }\end{array}$ & $\begin{array}{c}\text { ¡proliferação } \\
\text { (3, } 7 \text { e } 28 \text { dias) } \\
\uparrow \text { diferenciação } \\
\text { (14 e } 28 \text { dias) }\end{array}$ & (93) \\
\hline
\end{tabular}

A exposição à roda de corrida voluntária por longos períodos (1-8 meses) é igualmente capaz de estimular o número de células proliferativas $(83,95,96)$ e de neuroblastos $(82$, 83, 97-99) em camundongos adultos. Além disso, períodos longos de EFV são conhecidos por promoverem a neurogênese em animais adultos $(2,8,14,15,18,88$, $95,96)$ e idosos $(37,39)$. Poucos trabalhos abordam o efeito do EFV na proliferação e diferenciação neuronal após semanas ou meses do término do EF. Merkley e colaboradores (2014) encontraram alterações na sobrevivência celular e diferenciação neuronal, mas não na proliferação, quando avaliadas no período de 1 ou 5 semanas após o término do EFV (1 mês de exercício) (100). No entanto, alguns estudos não foram capazes de demonstrar aumento da proliferação celular após longos períodos de EFV (12 meses)(97)(99) de EFV em camundongos adultos. Um dos possíveis fatores responsáveis por essa divergência de resposta em relação à proliferação do GD é a condição social empregada nos diferentes trabalhos. Camundongos alojados em grupo expostos à roda de corrida demonstram aumento da proliferação celular (14) enquanto que,em camundongos alojados individualmente, este efeito do EFV não é observado $(97,99)$. A proliferação celular também pode ser diferenciada entre as espécies de roedores utilizadas. Por exemplo, Bednarczyk e colaboradores $(95,96)$ encontraram aumento da proliferação celular em camundongos CD1 que estavam em condições de isolamento durante longo período de EFV (Tabela 2).

Tabela 2 - Efeitos de períodos longos de EFV na Neuroplasticidade Estrutural Hipocampal

\begin{tabular}{|c|c|c|c|c|c|}
\hline Linhagem & Idade/gênero & Duração & Marcadores & Efeitos & Referências \\
\hline $\begin{array}{l}\text { Camundongo } \\
\text { C57BL/6 }\end{array}$ & $\begin{array}{l}3 \text { meses/ } \\
\text { fêmeas }\end{array}$ & $\begin{array}{c}2-4 \\
\text { meses }\end{array}$ & BrdU/NeuN & †neurogênese & (2) \\
\hline $\begin{array}{l}\text { Camundongo } \\
\text { C57BL/6 }\end{array}$ & $\begin{array}{l}3 \text { meses/ } \\
\text { fêmeas }\end{array}$ & 42 dias & BrdU/NeuN & $\uparrow$ neurogênese & $\begin{array}{l}\text { (14) } \\
\text { (8) }\end{array}$ \\
\hline Camundongo & $\begin{array}{l}\text { 6-8 semanas/ } \\
\text { fêmeas }\end{array}$ & 40 dias & BrdU/NeuN & ^neurogênese & (88) \\
\hline
\end{tabular}


C. P. N. Castro et al / Vittalle 29 n. 2 (2017) 57-78

\begin{tabular}{|c|c|c|c|c|c|}
\hline Mus domesticus & & & & $\uparrow B D N F$ no GD & \\
\hline $\begin{array}{l}\text { Camundongo } \\
\text { C57BL/6 }\end{array}$ & $\begin{array}{c}3 \text { e } 19 \text { meses/ } \\
\text { machos }\end{array}$ & 45 dias & $\begin{array}{c}\text { BrdU/NeuN/ } \\
\text { S100 } \beta\end{array}$ & neurogênese & (37) \\
\hline $\begin{array}{l}\text { Camundongo } \\
\text { C57BL/6 }\end{array}$ & $\begin{array}{l}74 \text { dias/ } \\
\text { machos }\end{array}$ & 32 dias & $\begin{array}{c}\text { DCX/ } \\
\text { Calretina }\end{array}$ & $\uparrow$ diferenciação & (83) \\
\hline $\begin{array}{l}\text { Camundongo } \\
\text { C57BL/6 }\end{array}$ & $\begin{array}{c}3 \text { meses/ } \\
\text { machos }\end{array}$ & 6 meses & $\begin{array}{l}\mathrm{BrDU} \\
\mathrm{DCX}\end{array}$ & $\begin{array}{c}\text { } p \text { proliferação } \\
\uparrow \text { diferenciação }\end{array}$ & (83) \\
\hline $\begin{array}{l}\text { Camundongo } \\
\text { C57BL/6 }\end{array}$ & $\begin{array}{l}114 \text { ou } 142 \\
\text { dias/ } \\
\text { Machos e } \\
\text { fêmeas }\end{array}$ & 54 dias & $\begin{array}{l}\text { BrdU/NeuN/ } \\
\text { S100 } \beta\end{array}$ & ¡neurogênese & (15) \\
\hline $\begin{array}{c}\text { Camundongo } \\
\text { CD1 }\end{array}$ & $\begin{array}{c}2 \text { meses/ } \\
\text { machos }\end{array}$ & 6 semanas & $\begin{array}{c}\text { BrDU e Ki-67 } \\
\text { DCX } \\
\text { BrdU/NeuN/ } \\
\text { GFAP }\end{array}$ & $\begin{array}{c}\text { †proliferação } \\
\uparrow \text { diferenciação } \\
\uparrow \text { neurogênese }\end{array}$ & (95) \\
\hline $\begin{array}{l}\text { Camundongo } \\
\text { CD1 }\end{array}$ & $\begin{array}{c}2 \text { meses/ } \\
\text { machos }\end{array}$ & 33 dias & $\begin{array}{c}\text { Ki-67 } \\
\text { DCX/Calretina } \\
\text { BrdU/NeuN/ } \\
\text { GFAP }\end{array}$ & $\begin{array}{c}\text { } p \text { proliferação } \\
\uparrow \text { diferenciação } \\
\uparrow \text { neurogênese }\end{array}$ & (96) \\
\hline $\begin{array}{l}\text { Camundongo } \\
\text { C57BL/6 }\end{array}$ & $\begin{array}{l}8 \text { semanas/ } \\
\text { fêmeas }\end{array}$ & 35 dias & $\begin{array}{l}\text { BrdU, IdU e CldU } \\
\text { DCX/calretina }\end{array}$ & $\uparrow$ diferenciação & $(82)$ \\
\hline $\begin{array}{l}\text { Camundongo } \\
\text { C57BL/6 }\end{array}$ & $\begin{array}{l}2 \text { meses/ } \\
\text { machos }\end{array}$ & 6 semanas & $\begin{array}{l}\text { Ki-67 } \\
\text { DCX }\end{array}$ & $\begin{array}{l}\uparrow \text { diferenciação } \\
\uparrow \text { BDNF no GD }\end{array}$ & (97) \\
\hline $\begin{array}{l}\text { Camundongo } \\
\text { C57BL/6 }\end{array}$ & $\begin{array}{l}9 \text { meses/ } \\
\text { fêmeas }\end{array}$ & 8 meses & $\begin{array}{c}\text { DCX } \\
\text { BrdU/NeuN }\end{array}$ & $\begin{array}{l}\uparrow \text { neurogênese } \\
\uparrow \text { BDNF no GD }\end{array}$ & (39) \\
\hline $\begin{array}{l}\text { Camundongo } \\
\text { BALB/cJ }\end{array}$ & $\begin{array}{l}10 \text { semanas/ } \\
\text { machos }\end{array}$ & 39 dias & $\begin{array}{c}\text { BrdU } \\
\text { (sobrevivência) }\end{array}$ & ^sobrevivência & (143) \\
\hline $\begin{array}{l}\text { Camundongo } \\
\text { C57BL/6 }\end{array}$ & $\begin{array}{c}2 \text { meses/ } \\
\text { machos }\end{array}$ & $\begin{array}{c}8-10 \\
\text { semanas }\end{array}$ & $\begin{array}{l}\mathrm{Ki}-67 \\
\mathrm{DCX}\end{array}$ & $\uparrow$ diferenciação & (99) \\
\hline $\begin{array}{l}\text { Camundongo } \\
\text { C57BL/6 }\end{array}$ & $\begin{array}{c}\text { 5-6 semanas/ } \\
\text { machos }\end{array}$ & 1 mês & BrdU & $\begin{array}{l}\uparrow \text { sobrevivencia } \\
\text { no GD dorsal }\end{array}$ & (144) \\
\hline $\begin{array}{l}\text { Rato Sprague- } \\
\text { dawley }\end{array}$ & $\begin{array}{l}200-250 \mathrm{~g} / \\
\text { machos }\end{array}$ & 1 mês & BrdU/NeuN & $\begin{array}{l}\uparrow \text { neurogênese } \\
\uparrow \mathrm{BDNF} \text { no GD }\end{array}$ & (18) \\
\hline $\begin{array}{l}\text { Rato Long } \\
\text { Evans }\end{array}$ & $\begin{array}{l}4 \text { semanas/ } \\
\text { machos }\end{array}$ & $\begin{array}{c}1 \text { mês } \\
\text { (avaliação } \\
1 \text { ou } 5 \\
\text { semanas e } \\
6 \text { ou } 9 \text { meses } \\
\text { após o } \\
\text { exercício) }\end{array}$ & $\begin{array}{c}\text { Ki-67 } \\
\text { DCX/IdU } \\
\text { (diferenciação) } \\
\text { CldU/CaBP } \\
\text { (sobrevivência e } \\
\text { maturação) }\end{array}$ & $\begin{array}{c}\uparrow \text { diferenciação } \\
\text { (1 semana) } \\
\uparrow \text { sobrevivência } \\
\text { e maturação } \\
\text { (5 semanas) }\end{array}$ & $(100)$ \\
\hline
\end{tabular}

Os dados descritos acima indicam que o EFV promove proliferação (3 dias) e diferenciação neuronal (12 horas) já durante períodos curtos, enquanto a formação de novos neurônios é descrita a partir de períodos mais longos de EFV. Portanto, o efeito do EFV na fase de proliferação/diferenciação não é necessariamente refletido na neurogênese; por exemplo, na ausência de um estímulo apropriado para sobrevivência, estes neurônios não se tornarão funcionais (27). Vale destacar que a presença da roda de corrida bloqueada como uma forma de enriquecimento ambiental também causa um aumento da proliferação celular (96). O enriquecimento ambiental é uma condição complexa, na qual os animais podem encontrar estímulos de diferentes modalidades (visuais, táteis, proprioceptivas) e este tipo de ambiente pode ser suficiente para estimular a proliferação celular. Por exemplo, Bednarczyk e colaboradores (2011) separaram os diversos componentes presentes no ambiente enriquecido e demonstraram que o efeito sobre a proliferação ocorre independente da atividade física (roda de 
corrida desbloqueada). No entanto, o aumento de neurônios imaturos positivos para DCX e de novos neurônios foi observado apenas em camundongos que se exercitaram, indicando que o EF é necessário para a maturação e sobrevivência dos neuroblastos pósmitóticos (96). Juntos, estes resultados mostram que o EF por si só (sem a contribuição do enriquecimento ambiental) influencia alguns dos estágios durante o processo de neurogênese (ou seja, as fases de diferenciação, maturação, e sobrevivência neuronal) (96). Além disso, em camundongos adultos a exposição à roda de corrida voluntária por 7 dias induz um aumento transiente nas células precursoras neurais e, também, reduz a quantidade de células DCX positivas que reentram na fase $S$ do ciclo celular (82), sugerindo que a corrida voluntária promove a neurogênese, não somente por aumentar a proliferação celular mas também por promover a saída das células progenitoras do ciclo celular.

O BDNF é uma neurotrofina que tem participação na neuroplasticidade hipocampal porque exerce um importante papel no crescimento e sobrevivência dos novos neurônios hipocampais $(101,102)$. Neeper e colaboradores (103) foram os primeiros a mostrar uma correlação positiva entre o EF e os níveis de BDNF. Eles observaram um aumento dos níveis do mRNA de BDNF no cerebelo, córtex caudal (análogo ao córtex visual e entorrinal em humanos) e no hipocampo de ratos que se exercitaram pelo período de 2-7 dias $(28,103)$. Após estes estudos iniciais, diversos trabalhos demonstraram que períodos curtos de EFV (período) são igualmente capazes de aumentar a expressão gênica de $\operatorname{BDNF}(3,16)$ e níveis proteicos de $\operatorname{BDNF}(29,104)$ no hipocampo. Além disso, períodos mais longos de exercício também alteram a expressão gênica e os níveis de proteína de $\operatorname{BDNF}(18,29,36,39,88,97)$.A análise morfológica hipocampal mostrou que as mudanças nos níveis de BDNF são localizadas na região neurogênica do GD (38). Entretanto, estudos adicionais mostraram que o EF eleva os níveis de BDNF em outras regiões encefálicas, como o cerebelo (28), amígdala(105), neocórtex $(28,103)$ e córtex perirrinal $(106,107)$ (Tabelas 1,2, 3 e 4).

\section{Exercício Físico aumenta a Plasticidade Sináptica Hipocampal Adulta}

Além da plasticidade estrutural, neurônios hipocampais maduros exibem plasticidade funcional ou sináptica sob a forma de fortalecimento, enfraquecimento e/ou remodelamento das sinapses existentes. Em 1973, Bliss e Lomo demonstraram que a estimulação elétrica de alta frequência num neurônio pré-sináptico hipocampal durante alguns segundos produz um aumento na magnitude da resposta pós-sináptica do neurônio estimulado. Este aumento pode durar algumas horas em animais anestesiados ou vários dias ou mesmo meses em animais acordados. Esse fenômeno foi denominado pelos pesquisadores de potenciação de longa duração (LTP, do inglês, long-term potentiation) (108). Do ponto de vista funcional, a LTP corresponde a um processo de facilitação do sistema nervoso, cujo estabelecimento depende da duração e da frequência do estímulo repetitivo; ou numa analogia, depende do 'treinamento', portanto de um processo de 'aprendizagem'. Outro tipo de plasticidade sináptica é a depressão de longa duração (LTD, do inglês, long-term depression), considerado um modelo de 'esquecimento' por reduzir a capacidade de um conjunto de sinapses de provocar uma resposta (109).

Além disso, outros sistemas moleculares e vias de sinalização moduladas pelo EF contribuem para o funcionamento e manutenção do SNC e, consequentemente, pela melhora na função sináptica e hipocampal, como o aumento de proteínas sinápticas (SYN1, SYP, SNAP-25, PSD95) $(26,30)$ e fatores de transcrição (CREB) importantes para a sobrevivência neuronal $(16,17)$ (tabela 3$)$. 
Tabela 3 - Efeitos de períodos curtos de EFV na Neuroplasticidade Funcional Hipocampal

\begin{tabular}{|c|c|c|c|c|}
\hline Linhagem & Idade/gênero & Duração & Efeitos & Referências \\
\hline $\begin{array}{l}\text { Camundongo } \\
\text { C57BL/6 }\end{array}$ & 3-5 semanas & $7-10$ dias & $\uparrow$ LTP no GD & (111) \\
\hline $\begin{array}{l}\text { Camundongo } \\
\text { C57BL/6 }\end{array}$ & $\begin{array}{l}\text { 8-9 semanas/ } \\
\text { machos }\end{array}$ & 28 dias & $\uparrow \mathrm{BDNF}$ & (104) \\
\hline $\begin{array}{l}\text { Camundongo } \\
\text { C57BL/6 }\end{array}$ & $\begin{array}{l}46 \text { dias/ } \\
\text { machos }\end{array}$ & 1 semana & $\begin{array}{c}\uparrow B D N F \\
\uparrow \text { genes relacionadas à } \\
\text { função sináptica (Calbl, } \\
\text { Fmrl, Cblnl, Synl, Syp); } \\
\downarrow \text { genes relacionadas a } \\
\text { função sináptica }(N c s)\end{array}$ & (3) \\
\hline $\begin{array}{c}\text { Rato } \\
\text { Sprague- } \\
\text { dawley }\end{array}$ & $\begin{array}{l}3 \text { meses/ } \\
\text { machos }\end{array}$ & $\begin{array}{l}3,7 \text { e } 28 \\
\text { dias }\end{array}$ & $\begin{array}{c}\uparrow \text { BDNF; } \\
\uparrow \text { genes relacionados à } \\
\text { função sináptica (STY1 e } \\
\text { SYT11) } \\
\uparrow \text { fatores de transcrição } \\
\text { (CREB) (3 e 7dias) } \\
\uparrow \text { expressão gênica de vias } \\
\text { de transdução (MAP-KI e } \\
\text { KII) (7 e } 28 \text { dias) no } \\
\text { hipocampo }\end{array}$ & (16) \\
\hline $\begin{array}{c}\text { Rato } \\
\text { Sprague- } \\
\text { dawley }\end{array}$ & $\begin{array}{l}3 \text { meses/ } \\
\text { machos }\end{array}$ & 3 e 7 dias & $\begin{array}{c}\uparrow \text { BDNF } \\
\uparrow \text { fatores de transcrição } \\
\text { (CREB) } \\
\uparrow \text { RNAm relacionadas à } \\
\text { função sináptica (SYN1) no } \\
\text { hipocampo }\end{array}$ & (17) \\
\hline $\begin{array}{l}\text { Rato } \\
\text { Sprague- } \\
\text { dawley }\end{array}$ & $\begin{array}{l}2 \text { meses/ } \\
\text { machos }\end{array}$ & 3 dias & $\begin{array}{l}\text { } p \text { proteínas relacionadas a } \\
\text { função sináptica (SYN1 e } \\
\text { SYP) no hipocampo }\end{array}$ & (26) \\
\hline $\begin{array}{l}\text { Rato } \\
\text { Sprague- } \\
\text { dawley }\end{array}$ & $\begin{array}{l}\text { 7-8 semanas/ } \\
\text { machos }\end{array}$ & $\begin{array}{l}2,4,7,14 \\
\text { e } 28 \text { dias } \\
\text { (exercício } \\
\text { s diários) } \\
7,14,21 \text { e } \\
28 \text { dias } \\
\text { (dias } \\
\text { alternado } \\
\text { s de } \\
\text { exercício) }\end{array}$ & $\uparrow B D N F$ no hipocampo & (29) \\
\hline $\begin{array}{l}\text { Rato } \\
\text { Sprague- } \\
\text { dawley }\end{array}$ & $\begin{array}{l}2 \text { meses/ } \\
\text { machos }\end{array}$ & 3-7 dias & $\begin{array}{c}\uparrow \text { proteínas relacionadas à } \\
\text { função sináptica (SNAP-25, } \\
\uparrow N R 2 b \text { e PSD95); } \downarrow \text { vias de } \\
\text { transdução (ERK); } \uparrow \text { vias de } \\
\text { transdução (MKP1 e } \\
\text { MAPK (p38)) no } \\
\text { hipocampo }\end{array}$ & (30) \\
\hline Rato & $10-12$ & & $\uparrow$ LTP no GD & \\
\hline $\begin{array}{l}\text { Sprague- } \\
\text { dawley }\end{array}$ & $\begin{array}{l}\text { semanas/ } \\
\text { machos }\end{array}$ & 10 dias & $\begin{array}{c}\text { (12-14 dias após o término do } \\
\text { exercício) }\end{array}$ & (10) \\
\hline $\begin{array}{l}\text { Rato } \\
\text { Sprague- } \\
\text { dawley }\end{array}$ & $\begin{array}{l}22 \text { dias/ } \\
\text { machos e } \\
\text { fêmeas }\end{array}$ & 13 dias & $\begin{array}{c}\uparrow \mathrm{LTP} \text { no GD apenas em } \\
\text { machos }\end{array}$ & (110) \\
\hline
\end{tabular}

Além das alterações morfológicas (neurogênese adulta), neurônios maduros 
hipocampais exibem plasticidade sináptica ou funcional sob a forma de remodelação dendrítica e sináptica. Modificações na plasticidade sináptica têm sido associadas com alterações morfológicas e facilitação ou inibição da LTP, comumente associada à formação de memória, e da LTD associada com o esquecimento (109).

Os efeitos benéficos do EF na plasticidade sináptica hipocampal in vitro foram primeiramente demonstrados em camundongos que apresentaram um aumento da LTP no GD após 2-4 meses de EFV(2). Estes achados na plasticidade sináptica hipocampal foram replicados em vários estudos in vitro e in vivo em que o $\operatorname{EFV}(18,93,110,111)$ ou forçado (112) aumentou a LTP no GD hipocampal em roedores (Tabela 4).

Tabela 4 - Efeitos de períodos longos de EFV na Neuroplasticidade Funcional Hipocampal

\begin{tabular}{|c|c|c|c|c|}
\hline Linhagem & Idade/gênero & Duraçãa & Efeitos & Referências \\
\hline $\begin{array}{l}\text { Camundongo } \\
\text { C57BL/6 }\end{array}$ & $\begin{array}{l}3 \text { meses } \\
\text { Fêmeas }\end{array}$ & $\begin{array}{l}2-4 \\
\text { meses }\end{array}$ & 个LTP no GD & (2) \\
\hline $\begin{array}{l}\text { Camundongo } \\
\text { C57BL/6 }\end{array}$ & $\begin{array}{l}2 \text { meses } \\
\text { Machos }\end{array}$ & 3 meses & $\begin{array}{l}\text { ¡BDNF (logo após o } \\
\text { exercício, } 1 \text { e } 2 \text { semanas } \\
\text { após o período de } \\
\text { exercício) }\end{array}$ & (36) \\
\hline $\begin{array}{l}\text { Camundongo } \\
\text { C57BL/6 }\end{array}$ & $\begin{array}{l}2 \text { meses } \\
\text { Machos }\end{array}$ & $\begin{array}{c}\text { 6-8 } \\
\text { semanas }\end{array}$ & $\begin{array}{c}\uparrow \text { volume de matéria } \\
\text { cinzenta hipocampal } \\
\text { (VBM) }\end{array}$ & (145) \\
\hline $\begin{array}{l}\text { Camundongo } \\
\text { C57BL/6 }\end{array}$ & $\begin{array}{l}2 \text { meses } \\
\text { Machos }\end{array}$ & $\begin{array}{c}8-10 \\
\text { semanas }\end{array}$ & $\begin{array}{c}\uparrow \text { volume de matéria } \\
\text { cinzenta hipocampal - } \\
\text { GD, CA1, } 2 \text { e } 3 \text { (VBM) }\end{array}$ & (99) \\
\hline $\begin{array}{l}\text { Rato Sprague- } \\
\text { dawley }\end{array}$ & $\begin{array}{l}250-500 \mathrm{~g} / \\
\text { machos }\end{array}$ & 1 mês & $\begin{array}{l}\uparrow \text { LTP e STP no GD } \\
\downarrow \text { limiar de indução da } \\
\text { LTPno GD }\end{array}$ & (18) \\
\hline $\begin{array}{l}\text { Rato Sprague- } \\
\text { dawley }\end{array}$ & $\begin{array}{l}\text { 7-8 semanas/ } \\
\text { machos }\end{array}$ & $\begin{array}{l}90 \text { dias } \\
\text { (exercício } \\
\mathrm{s} \text { diários) }\end{array}$ & $\uparrow B D N F$ no hipocampo & (29) \\
\hline $\begin{array}{c}\text { Rato Sprague- } \\
\text { dawley }\end{array}$ & $\begin{array}{l}2 \text { meses } \\
\text { Machos }\end{array}$ & 56 dias & $\uparrow \mathrm{LTP}$ no GD & (93) \\
\hline
\end{tabular}

A melhora no aprendizado e memória induzido pelo EFV está diretamente associada com a atividade dependente da plasticidade sináptica, como demonstrado por van Praag e colaboradores (2), em que o aumento da LTP foi associado com a melhora na memória espacial, avaliado através do teste do labirinto aquático de Morris em camundongos adultos. Em relação à duração do EFV e seu efeito sobre a plasticidade sináptica, um aumento da LTP no GD foi demonstrado após 7-10 dias de exposição à roda de corrida em camundongos jovens de 3 a 5 semanas de idade (111) (Tabela 3).

Farmer e colaboradores (18) observaram um aumento da LTP no GD após 1 mês de EFV em ratos jovens (1mês de idade), enquanto Patten e colaboradores (93) demonstraram este aumento apenas após 56 dias de EFV e não encontraram diferenças na LTP em períodos mais curtos de exposição à roda de corrida (3,7, 14 ou 28dias) em ratos adultos. Apenas um trabalho avaliou o efeito do exercício na LTP dias após o término do EFV. Bruel-Jungerman e colaboradores (10) demonstraram aumento da LTP no GD no período de 12-14 dias após o término do EFV (10 dias de exposição à roda de corrida) em ratos adultos (Tabela 4).

O EFV foi capaz de aumentar a LTP em ratos machos adolescentes, e este resultado não foi verificado em fêmeas, revelando, então, que os machos adolescentes são mais sensíveis aos efeitos do EFV sobre a plasticidade sináptica (10). Além disso, o aumento 


\section{P. N. Castro et al / Vittalle 29 n. 2 (2017) 57-78}

de LTP observado após EFV é consistente com um aumento nos níveis de BDNF hipocampal (18), o que pode modular a plasticidade sináptica através da ativação de cascadas de sinalização intracelular.

Além destas alterações funcionais abordadas acima, sabe-se que diferentes sistemas moleculares e vias de sinalização podem estar envolvidos no efeito do EF sobre o funcionamento do SNC. Estas alterações contribuem para uma melhora na atividade sináptica e, consequentemente, na função hipocampal. O EF foi capaz de aumentar a expressão gênica de proteínas associadas à função sináptica $(3,16,17,26,30)$, expressão gênica e de proteínas de componentes de vias de sobrevivência como a MAPK $(16,30)$ e expressão gênica de fatores de transcrição como o CREB no hipocampo de animais adultos $(16,17)$ (Tabela 3$)$.

Estes resultados demonstram que o EFV é capaz de modular a expressão de genes e níveis de proteína associados à plasticidade neuronal em períodos curtos de exposição, indicando um efeito agudo do EF. O aumento da expressão gênica de sintaxina(STY1) e sinaptotagmina (SYT11) no hipocampo, que são proteínas relacionadas à função sináptica, são demonstradas após 3 dias de exposição à roda de corrida (16), enquanto um aumento na expressão de outras proteínas sinápticas como sinapsina (SYN1) e sinaptofisina (SYP) são demonstradas após 7 dias de exposição (3) em roedores adultos. Este efeito do curto período do EFV também pode ser verificado através do aumento dos níveis proteicos de SYN1, SYP, SNAP-25 e PSD95 no hipocampo de ratos adultos após 3 dias de $\operatorname{EFV~}(26,30)$. Um efeito agudo do EF também pode ser verificado através do aumento do fator de transcrição CREB após 3 e 7 dias de exposição à roda de corrida em ratos adultos $(16,17)$ (Tabela 3$)$.

Além das alterações moleculares, alterações estruturais provocadas pelo EF também foram demonstradas. Bierderman e colaboradores (14) demonstraram que 6-8 semanas de EFV são capazes de aumentar o volume hipocampal, indicando um efeito regional (ou estrutura específica) do EFV. Em outro estudo mais recente, houve aumento do volume hipocampal após 8-10 semanas de exposição à roda de corrida, e este volume possivelmente estaria relacionado com o aumento da neurogênese demonstrado em camundongos adultos (99) (Tabela 4).

\section{O Exercício Físico como Estratégia Terapêutica em Humanos}

Em humanos, uma extensa pesquisa sugere a importância do EF para a saúde geral e para a função cognitiva. $\mathrm{O} E F$ pode ser considerado um tratamento não farmacológico capaz de reduzir o risco de muitas doenças, incluindo o acidente vascular cerebral, hipertensão, e transtornos de humor, tais como a depressão e demência (44, 48, 113 118). Sabe-se que a prática regular do EF resulta em adaptações orgânicas, decorrentes de alterações metabólicas, endócrinas e neuro-humorais, responsáveis pela melhora da saúde física e mental $(117,119,120)$. Vale ressaltar que os tipos de EFV em humanos são bastante variáveis (por exemplo, diferentes esportes) e variam muito quanto à intensidade e duração. Nesta revisão, a maioria dos artigos utilizou a caminhada como EFV.

O EF é capaz de aumentar o aprendizado e a memória em crianças $(121,122)$, adolescentes, (123) adultos (124) e em idosos (5, 114). Efeitos positivos do EFV também são extensivamente relatados para melhora da depressão e da ansiedade (44, 45). Além disso, o EFV pode retardar déficits cognitivos ocasionados pelo envelhecimento $(125,126)$. Estas alterações comportamentais podem estar relacionadas às alterações na plasticidade estrutural e sináptica hipocampal, provocadas pelo exercício. No entanto, há uma grande dificuldade para a avaliação desta característica 
em humanos. Uma das formas de estudar as mudanças na plasticidade cerebral decorrentes da prática regular do EF em humanos é o uso de métodos de neuroimagem não invasivos. Pereira e colaboradores (127) demonstraram um aumento do fluxo sanguíneo no GD hipocampal de indivíduos adultos após 3 meses de EFV. Os autores sugerem que este aumento estaria relacionado com neurogênese induzida pelo EF (127). Um aumento da conectividade hipocampal também foi demonstrado em indivíduos saudáveis após um ano de EFV, o que poderia ser considerado um importante efeito do EF na plasticidade hipocampal (128).

Como descrito nesta revisão, o BDNF é de extrema importância para a função hipocampal. Estudos em roedores demonstram que os níveis de BDNF hipocampais são responsivos ao $\mathrm{EF}(16,29,104)$. Em humanos, diversos estudos demonstram aumento dos níveis de BDNF sérico e outros fatores de crescimento em indivíduos após o exercício $(5,128)$.

Um fato importante que merece destaque é que, embora o hipocampo seja especialmente suscetível ao envelhecimento e às doenças neurodegenerativas relacionadas à atrofia e disfunção, ele é também altamente plástico e responsivo ao EF. Um estudo longitudinal demonstrou que 1 ano de treinamento aeróbico (de intensidade moderada-intensa) em indivíduos saudáveis (55-80 anos) é capaz de provocar aumento do volume hipocampal, o que está correlacionado com a elevação dos níveis plasmáticos de BDNF (5).

Vale ressaltar que o aumento do fluxo sanguíneo cerebral ocasionado pela prática do EF é responsável, ao menos em parte, pelos efeitos benéficos do EF na neuroplasticidade sináptica e na função cognitiva, porque melhora o transporte de oxigênio, nutrientes e neurotrofinas. A prática regular de EF é capaz de aumentar o fluxo sanguíneo hipocampal em indivíduos idosos saudáveis (70-85 anos) que se exercitaram por 4 meses (129).

A maioria dos dados de estudos clínicos apontam efeitos benéficos do EF para a memória. $\mathrm{O} \mathrm{EFV}$ foi relacionado a uma melhora no aprendizado espacial em jovens entre 15 e 18 anos de idade e esta melhora foi associada a um aumento do volume hipocampal (123). Além disso, em indivíduos idosos saudáveis, foi demonstrado que o condicionamento cardiovascular está associado a uma melhora na memória espacial (130) e a um menor risco de desenvolvimento de declínio cognitivo relacionado ao envelhecimento (131) (Tabela 5).

No entanto, vários estudos demonstram que, além do hipocampo, outras regiões cerebrais também podem ser ativadas pelo EFV. Alguns estudos demonstraram que indivíduos que praticavam $\mathrm{EF}$ obtiveram um melhor desempenho em testes que avaliavam funções executivas (132-136), sugerindo que o EF é capaz de afetar positivamente o hipocampo e o córtex pré-frontal. Em particular, estudos que utilizaram ressonância magnética funcional (fMRI) demonstraram aumento da atividade neural no córtex pré-frontal durante a execução de testes mais difíceis $(133,137)$.

Tabela 5 - Efeito do EFV na Neuroplasticidade Estrutural Hipocampal e na modulação dos comportamentos dependentes do hipocampo

\begin{tabular}{|c|c|c|c|c|c|}
\hline \multirow{2}{*}{$\begin{array}{l}\text { Idade/ } \\
\text { Gênero }\end{array}$} & \multirow[t]{2}{*}{ Duração } & \multicolumn{3}{|c|}{ Resultados } & \multirow[t]{2}{*}{ Referência } \\
\hline & & Estruturais & Comportamental & Outros & \\
\hline $\begin{array}{l}\geq 65 \\
\text { anos/ } \\
\text { Mulheres }\end{array}$ & 6-8 anos & & $\begin{array}{l}\text { Prevenção do } \\
\text { declínio cognitivo } \\
\text { decorrente do } \\
\text { envelhecimento }\end{array}$ & & (131) \\
\hline
\end{tabular}


C. P. N. Castro et al / Vittalle 29 n. 2 (2017) 57-78

\begin{tabular}{|c|c|c|c|c|c|}
\hline $\begin{array}{l}21-45 \\
\text { anos/ } \\
\text { Homens e } \\
\text { Mulheres }\end{array}$ & 3 meses & & $\begin{array}{l}\text { Melhora da função } \\
\text { cognitiva }\end{array}$ & $\begin{array}{l}\text { } \text { Fluxo sanguíneo no } \\
\text { GD } \\
\text { (MRI) }\end{array}$ & (127) \\
\hline $\begin{array}{l}18-70 \\
\text { anos/ } \\
\text { Homens e } \\
\text { mulheres }\end{array}$ & $\begin{array}{l}10 \\
\text { semanas } \\
(3-7 \\
\text { d/semana })\end{array}$ & & $\begin{array}{l}\text { Melhora da função } \\
\text { cognitiva }\end{array}$ & & (34) \\
\hline $\begin{array}{l}70-85 \\
\text { anos/ } \\
\text { Homens e }\end{array}$ & 4 meses & & & $\begin{array}{l}\uparrow \text { Fluxo sanguíneo } \\
\text { hipocampal } \\
\text { (MRI) }\end{array}$ & (139) \\
\hline $\begin{array}{l}\geq 65 \\
\text { anos/ } \\
\text { Homens e } \\
\text { Mulheres }\end{array}$ & 9 anos & $\begin{array}{l}\uparrow \text { Volume } \\
\text { hipocampal } \\
\text { (MRI) }\end{array}$ & $\begin{array}{l}\text { Redução do declínio } \\
\text { cognitivo }\end{array}$ & & (118) \\
\hline $\begin{array}{l}55-80 \\
\text { anos/ } \\
\text { Homens e } \\
\text { Mulheres }\end{array}$ & $\begin{array}{l}1 \text { ano } \\
\text { (3d/seman } \\
\text { a) }\end{array}$ & $\begin{array}{l}\uparrow \text { Volume } \\
\text { hipocampal } \\
\text { (MRI) }\end{array}$ & $\uparrow$ Memória espacial & $\begin{array}{l}\uparrow \text { Condicionamento } \\
\text { físico } \\
\uparrow \mathrm{BDNF}\end{array}$ & (5) \\
\hline $\begin{array}{l}15-18 \\
\text { anos/ } \\
\text { Homens }\end{array}$ & & $\begin{array}{l}\uparrow \text { Volume } \\
\text { hipocampal } \\
\text { (MRI) }\end{array}$ & $\begin{array}{l}\text { Melhora na } \\
\text { aprendizagem } \\
\text { espacial }\end{array}$ & & (123) \\
\hline $\begin{array}{l}55-80 \\
\text { anos/ } \\
\text { Homens e } \\
\text { Mulheres }\end{array}$ & 1 ano & $\begin{array}{l}\uparrow \text { conectividade } \\
\text { hipocampal } \\
\text { (conectividade } \\
\text { funcional) } \\
\text { (MRI) }\end{array}$ & & $\uparrow B D N F$, IGF e VEGF & (128) \\
\hline
\end{tabular}

Interessantemente, muitos estudos clínicos têm demonstrado os efeitos do $\mathrm{EF}$ não somente em indivíduos saudáveis, mas também em indivíduos com doenças neuropsiquiátricas e neurodegenerativas $(114,138)$. Sabe-se que o envelhecimento está associado ao aumento da atrofia e disfunção hipocampal e que estas alterações estão ligadas aos prejuízos na memória em indivíduos idosos (114). Como demonstrado nos trabalhos presentes nesta revisão, o EF é capaz de aumentar o volume hipocampal (5, 118) e o fluxo sanguíneo nesta estrutura em indivíduos idosos (139), levando a uma melhora na função cognitiva (5), sendo capaz de retardar o declínio cognitivo decorrente do envelhecimento (131) e o aparecimento da demência na doença de Alzheimer (138, 140).

\section{Considerações finais}

Várias evidências pré-clínicas mostram que o EFV promove a plasticidade estrutural e funcional do hipocampo adulto. O EF é capaz de modular uma série de processos moleculares e celulares, levando a uma melhora da função hipocampal e, consequentemente, conferindo alteração comportamental (principalmente ligada à função cognitiva, como demonstrada nessa revisão). A plasticidade hipocampal está relacionada ao processo de envelhecimento, com doenças neurodegenerativas e com transtornos de humor, tal como a depressão, justificando o estudo dos diversos mecanismos envolvidos no controle deste processo e a busca por terapias que possam afetar diretamente o hipocampo. Em roedores, a roda de corrida é o modelo mais utilizado para as avaliações dos efeitos do EFV e, claramente, são evidenciados inúmeros efeitos positivos no SNC. Porém, a extrapolação de resultados de modelos animais para humanos requer a validação destes efeitos do $\mathrm{EF}$ na neurogênese em 
indivíduos que praticam o EFV. Além do estudo na neurogênese em humanos in vivo não ser metodologicamente possível, outros fatores dificultam a translação dos estudos animais para humanos. Entre estes, podemos destacar os diferentes protocolos de EFV existentes, os diferentes modelos animais empregados (camundongos e ratos), as condições de alojamento do animal (isolamento ou não) utilizadas nos variados protocolos. E, principalmente, somados a isso, a forma como o EFV modula o processo de neurogênese adulta e o exato papel deste processo nos comportamentos ligados ao hipocampo, como aprendizagem, memória e depressão, que ainda não estão completamente elucidados. Porém, apesar das alterações celulares e químicas ainda serem desconhecidas em seres humanos, os amplos efeitos do EFV para a estrutura e função hipocampal observados em roedores reforça que a pratica do EFV poderia ser sugerida com a potencialidade de alcançar efeitos neurológicos em humanos semelhantes aos encontrados nos modelos animais, em condições normais de saúde para a manutenção da plasticidade hipocampal, além de poder alterar o curso de doenças ou danos decorrentes do envelhecimento associados a prejuízos na plasticidade do SNC e, mais especificamente, no hipocampo. Portanto, o EF é um comportamento simples que pode ser amplamente praticado em qualquer idade, com o objetivo de melhorar o aprendizado e a memória e retardar o declínio cognitivo associado ao envelhecimento, e prevenir transtornos psiquiátricos que podem estar diretamente ligados à plasticidade hipocampal, desse modo, aumentando a qualidade de vida.

Lista de Abreviações: BDNF, fator neurotrófico derivado do encéfalo; BrdU, 5-bromo-2'deoxiuridina; CaBP, calbindina D-28, marcador de maturação neuronal; Calb1, calbindin; Cbln1, cerebelin 1 precursor protein; CldU, 5-chloro-2'-deoxyuridine; CREB, cyclic AMP responsive element-binding protein; DCX, doublecortina, marcador de diferenciação neuronal; EFV, exercício físico voluntário; ERK, extracellular signal-regulated kinases;Fmr1, fragile $\mathrm{X}$ mental retardation syndrome 1 homolog; GD, giro denteado; GFAP, glial fibrillary acidic protein; IdU, 5-iodo-2'-deoxyuridine; IGF, Fator de crescimento Insulina-1; ki-67, marcador endógeno de proliferação celular; LTP, potenciação de longa duração; MAPK, mitogen activated protein kinases; MKP1, phosphatase mitogen activated kinase phosphatase 1; MRI, imagem de ressonância magnética; Ncs, neuronal calcium sensor 1; NeuN, neuronal nuclei; NeuroD, marcador endógeno para diferenciação neuronal; NR2b, proteína pós-sináptica; PCNA, proliferating cell nuclear antigen; pH3, phospho-histone 3, marcador de proliferação celular; PSD95, proteína pós- sináptica;SNAP25, synaptosome-associated protein-25; STP, potenciação de curta duração; S100ß, proteina expressa por astrócitos; STY1, syntaxin 1A; STY11, synaptotagmin XI; SYN1,synapsin I; SYP, synapthophysin; VBM-voxel-based morphometry; VEGF, fator de crescimento endotelial vascular.

\section{Referências Bibliográficas}

1. Caspersen CJ, Powell KE, Christenson GM. Physical activity, exercise, and physical fitness: definitions and distinctions for health-related research. Public Health Rep. 1985;100(2):126-31.

2. van Praag H, Christie BR, Sejnowski TJ, Gage FH. Running enhances neurogenesis, learning, and long-term potentiation in mice. Proc Natl Acad Sci U S A. 1999;96(23):13427-31.

3. Abel JL, Rissman EF. Running-induced epigenetic and gene expression changes in the adolescent brain. Int J Dev Neurosci. 2013;31(6):382-90.

4. Yau SY, Li A, Hoo RL, Ching YP, Christie BR, Lee TM, et al. Physical exercise-induced hippocampal neurogenesis and antidepressant effects are mediated by the adipocyte hormone adiponectin. Proceedings of the National Academy of Sciences of the United States of America. 2014;111(44):158105 .

5. Erickson KI, Voss MW, Prakash RS, Basak C, Szabo A, Chaddock L, et al. Exercise training increases size of hippocampus and improves memory. Proceedings of the National Academy of Sciences 


\section{P. N. Castro et al / Vittalle 29 n. 2 (2017) 57-78}

of the United States of America. 2011;108(7):3017-22.

6. Voss MW, Heo S, Prakash RS, Erickson KI, Alves H, Chaddock L, et al. The influence of aerobic fitness on cerebral white matter integrity and cognitive function in older adults: results of a one-year exercise intervention. Hum Brain Mapp. 2013;34(11):2972-85.

7. Arida RM, Scorza FA, Gomes da Silva S, Cysneiros RM, Cavalheiro EA. Exercise paradigms to study brain injury recovery in rodents. Am J Phys Med Rehabil. 2011;90(6):452-65.

8. Brown J, Cooper-Kuhn CM, Kempermann G, Van Praag H, Winkler J, Gage FH, et al. Enriched environment and physical activity stimulate hippocampal but not olfactory bulb neurogenesis. Eur $\mathbf{J}$ Neurosci. 2003;17(10):2042-6.

9. Chakraborty R, Chatterjee A, Choudhary S, Chakraborty PK. Neuroplasticity--a paradigm shift in neurosciences. J Indian Med Assoc. 2007;105(9):513-4, 6-8, 20-1.

10. Bruel-Jungerman E, Veyrac A, Dufour F, Horwood J, Laroche S, Davis S. Inhibition of PI3K-Akt signaling blocks exercise-mediated enhancement of adult neurogenesis and synaptic plasticity in the dentate gyrus. PLoS One. 2009;4(11):e7901.

11. Kuhn HG, Dickinson-Anson H, Gage FH. Neurogenesis in the dentate gyrus of the adult rat: agerelated decrease of neuronal progenitor proliferation. J Neurosci. 1996;16(6):2027-33.

12. Tanapat P, Galea LA, Gould E. Stress inhibits the proliferation of granule cell precursors in the developing dentate gyrus. Int J Dev Neurosci. 1998;16(3-4):235-9.

13. Ekdahl CT, Claasen JH, Bonde S, Kokaia Z, Lindvall O. Inflammation is detrimental for neurogenesis in adult brain. Proc Natl Acad Sci U S A. 2003;100(23):13632-7.

14. van Praag H, Kempermann G, Gage FH. Running increases cell proliferation and neurogenesis in the adult mouse dentate gyrus. Nat Neurosci. 1999;2(3):266-70.

15. Clark PJ, Brzezinska WJ, Thomas MW, Ryzhenko NA, Toshkov SA, Rhodes JS. Intact neurogenesis is required for benefits of exercise on spatial memory but not motor performance or contextual fear conditioning in C57BL/6J mice. Neuroscience. 2008;155(4):1048-58.

16. Molteni R, Ying Z, Gomez-Pinilla F. Differential effects of acute and chronic exercise on plasticityrelated genes in the rat hippocampus revealed by microarray. Eur J Neurosci. 2002;16(6):1107-16.

17. Vaynman S, Ying Z, Gomez-Pinilla F. Interplay between brain-derived neurotrophic factor and signal transduction modulators in the regulation of the effects of exercise on synaptic-plasticity. Neuroscience. 2003;122(3):647-57.

18. Farmer J, Zhao X, van Praag H, Wodtke K, Gage FH, Christie BR. Effects of voluntary exercise on synaptic plasticity and gene expression in the dentate gyrus of adult male Sprague-Dawley rats in vivo. Neuroscience. 2004;124(1):71-9.

19. Holschneider DP, Yang J, Guo Y, Maarek JM. Reorganization of functional brain maps after exercise training: Importance of cerebellar-thalamic-cortical pathway. Brain Res. 2007;1184:96-107.

20. Tong L, Shen H, Perreau VM, Balazs R, Cotman CW. Effects of exercise on gene-expression profile in the rat hippocampus. Neurobiol Dis. 2001;8(6):1046-56.

21. Duffy SN, Craddock KJ, Abel T, Nguyen PV. Environmental enrichment modifies the PKAdependence of hippocampal LTP and improves hippocampus-dependent memory. Learn Mem. 2001;8(1):26-34.

22. Kronenberg G, Reuter K, Steiner B, Brandt MD, Jessberger S, Yamaguchi M, et al. Subpopulations of proliferating cells of the adult hippocampus respond differently to physiologic neurogenic stimuli. J Comp Neurol. 2003;467(4):455-63.

23. Inal M, Akyuz F, Turgut A, Getsfrid WM. Effect of aerobic and anaerobic metabolism on free radical generation swimmers. Med Sci Sports Exerc. 2001;33(4):564-7.

24. Ding Q, Vaynman S, Akhavan M, Ying Z, Gomez-Pinilla F. Insulin-like growth factor I interfaces with brain-derived neurotrophic factor-mediated synaptic plasticity to modulate aspects of exerciseinduced cognitive function. Neuroscience. 2006;140(3):823-33.

25. Ang ET, Dawe GS, Wong PT, Moochhala S, Ng YK. Alterations in spatial learning and memory after forced exercise. Brain Res. 2006;1113(1):186-93.

26. Vaynman SS, Ying Z, Yin D, Gomez-Pinilla F. Exercise differentially regulates synaptic proteins associated to the function of BDNF. Brain Res. 2006;1070(1):124-30. 
27. Kempermann G, Fabel K, Ehninger D, Babu H, Leal-Galicia P, Garthe A, et al. Why and how physical activity promotes experience-induced brain plasticity. Front Neurosci. 2010;4:189.

28. Neeper SA, Gomez-Pinilla F, Choi J, Cotman CW. Physical activity increases mRNA for brainderived neurotrophic factor and nerve growth factor in rat brain. Brain Res. 1996;726(1-2):49-56.

29. Berchtold NC, Chinn G, Chou M, Kesslak JP, Cotman CW. Exercise primes a molecular memory for brain-derived neurotrophic factor protein induction in the rat hippocampus. Neuroscience. 2005;133(3):853-61.

30. $\mathrm{Hu}$ S, Ying Z, Gomez-Pinilla F, Frautschy SA. Exercise can increase small heat shock proteins (sHSP) and pre- and post-synaptic proteins in the hippocampus. Brain Res. 2009;1249:191-201.

31. Soares DD, Coimbra CC, Marubayashi U. Tryptophan-induced central fatigue in exercising rats is related to serotonin content in preoptic area. Neurosci Lett. 2007;415(3):274-8.

32. Eddy MC, Stansfield KJ, Green JT. Voluntary exercise improves performance of a discrimination task through effects on the striatal dopamine system. Learn Mem. 2014;21(7):334-7.

33. Schmidt-Kassow M, Deusser M, Thiel C, Otterbein S, Montag C, Reuter M, et al. Physical exercise during encoding improves vocabulary learning in young female adults: a neuroendocrinological study. PLoS One. 2013;8(5):e64172.

34. Masley S, Roetzheim R, Gualtieri T. Aerobic exercise enhances cognitive flexibility. J Clin Psychol Med Settings. 2009;16(2):186-93.

35. Cotman CW, Berchtold NC. Physical activity and the maintenance of cognition: learning from animal models. Alzheimers Dement. 2007;3(2 Suppl):S30-7.

36. Berchtold NC, Castello N, Cotman CW. Exercise and time-dependent benefits to learning and memory. Neuroscience. 2010;167(3):588-97.

37. van Praag H, Shubert T, Zhao C, Gage FH. Exercise enhances learning and hippocampal neurogenesis in aged mice. J Neurosci. 2005;25(38):8680-5.

38. Vaynman S, Ying Z, Gomez-Pinilla F. Exercise induces BDNF and synapsin I to specific hippocampal subfields. J Neurosci Res. 2004;76(3):356-62.

39. Marlatt MW, Potter MC, Lucassen PJ, van Praag H. Running throughout middle-age improves memory function, hippocampal neurogenesis, and BDNF levels in female C57BL/6J mice. Dev Neurobiol. 2012;72(6):943-52.

40. Bjornebekk A, Mathe AA, Brene S. The antidepressant effect of running is associated with increased hippocampal cell proliferation. Int J Neuropsychopharmacol. 2005;8(3):357-68.

41. Greenwood BN, Foley TE, Day HE, Campisi J, Hammack SH, Campeau S, et al. Freewheel running prevents learned helplessness/behavioral depression: role of dorsal raphe serotonergic neurons. J Neurosci. 2003;23(7):2889-98.

42. Trejo JL, Llorens-Martin MV, Torres-Aleman I. The effects of exercise on spatial learning and anxiety-like behavior are mediated by an IGF-I-dependent mechanism related to hippocampal neurogenesis. Mol Cell Neurosci. 2008;37(2):402-11.

43. Salam JN, Fox JH, Detroy EM, Guignon MH, Wohl DF, Falls WA. Voluntary exercise in C57 mice is anxiolytic across several measures of anxiety. Behav Brain Res. 2009;197(1):31-40.

44. Dimeo F, Bauer M, Varahram I, Proest G, Halter U. Benefits from aerobic exercise in patients with major depression: a pilot study. Br J Sports Med. 2001;35(2):114-7.

45. Martinsen EW, Medhus A, Sandvik L. Effects of aerobic exercise on depression: a controlled study. Br Med J (Clin Res Ed). 1985;291(6488):109.

46. Farmer ME, Locke BZ, Moscicki EK, Dannenberg AL, Larson DB, Radloff LS. Physical activity and depressive symptoms: the NHANES I Epidemiologic Follow-up Study. Am J Epidemiol. 1988;128(6):1340-51.

47. Babyak M, Blumenthal JA, Herman S, Khatri P, Doraiswamy M, Moore K, et al. Exercise treatment for major depression: maintenance of therapeutic benefit at 10 months. Psychosom Med. 2000;62(5):6338 .

48. Strawbridge WJ, Deleger S, Roberts RE, Kaplan GA. Physical activity reduces the risk of subsequent depression for older adults. Am J Epidemiol. 2002;156(4):328-34.

49. Altman J, Das GD. Autoradiographic and histological evidence of postnatal hippocampal neurogenesis in rats. J Comp Neurol. 1965;124(3):319-35. 


\section{P. N. Castro et al / Vittalle 29 n. 2 (2017) 57-78}

50. Gage FH. Structural plasticity of the adult brain. Dialogues Clin Neurosci. 2004;6(2):135-41.

51. Fuchs E, Flugge G. Adult neuroplasticity: more than 40 years of research. Neural Plast. 2014;2014:541870.

52. Knierim JJ. The hippocampus. Curr Biol. 2015;25(23):R1116-21.

53. Gage FH. Neurogenesis in the adult brain. J Neurosci. 2002;22(3):612-3.

54. Kempermann G, Wiskott L, Gage FH. Functional significance of adult neurogenesis. Curr Opin Neurobiol. 2004;14(2):186-91.

55. Duan X, Kang E, Liu CY, Ming GL, Song H. Development of neural stem cell in the adult brain. Curr Opin Neurobiol. 2008;18(1):108-15.

56. Deng W, Aimone JB, Gage FH. New neurons and new memories: how does adult hippocampal neurogenesis affect learning and memory? Nat Rev Neurosci. 2010;11(5):339-50.

57. Kempermann G, Jessberger S, Steiner B, Kronenberg G. Milestones of neuronal development in the adult hippocampus. Trends Neurosci. 2004;27(8):447-52.

58. Seri B, Garcia-Verdugo JM, McEwen BS, Alvarez-Buylla A. Astrocytes give rise to new neurons in the adult mammalian hippocampus. J Neurosci. 2001;21(18):7153-60.

59. Kempermann G, Song H, Gage FH. Neurogenesis in the Adult Hippocampus. Cold Spring Harb Perspect Biol. 2015;7(9):a018812.

60. Sierra A, Encinas JM, Deudero JJ, Chancey JH, Enikolopov G, Overstreet-Wadiche LS, et al. Microglia shape adult hippocampal neurogenesis through apoptosis-coupled phagocytosis. Cell Stem Cell. 2010;7(4):483-95.

61. Cooper-Kuhn CM, Kuhn HG. Is it all DNA repair? Methodological considerations for detecting neurogenesis in the adult brain. Brain Res Dev Brain Res. 2002;134(1-2):13-21.

62. Eisch AJ, Mandyam CD. Adult neurogenesis: can analysis of cell cycle proteins move us "Beyond BrdU"? Curr Pharm Biotechnol. 2007;8(3):147-65.

63. Sarnat HB. Immunocytochemical markers of neuronal maturation in human diagnostic neuropathology. Cell Tissue Res. 2015;359(1):279-94.

64. Zhao C, Deng W, Gage FH. Mechanisms and functional implications of adult neurogenesis. Cell. 2008;132(4):645-60.

65. Malberg JE, Eisch AJ, Nestler EJ, Duman RS. Chronic antidepressant treatment increases neurogenesis in adult rat hippocampus. J Neurosci. 2000;20(24):9104-10.

66. Manev R, Uz T, Manev H. Fluoxetine increases the content of neurotrophic protein S100beta in the rat hippocampus. Eur J Pharmacol. 2001;420(2-3):R1-2.

67. Aberg MA, Aberg ND, Hedbacker H, Oscarsson J, Eriksson PS. Peripheral infusion of IGF-I selectively induces neurogenesis in the adult rat hippocampus. J Neurosci. 2000;20(8):2896-903.

68. Kempermann G, Kuhn HG, Gage FH. More hippocampal neurons in adult mice living in an enriched environment. Nature. 1997;386(6624):493-5.

69. Spalding KL, Bergmann O, Alkass K, Bernard S, Salehpour M, Huttner HB, et al. Dynamics of hippocampal neurogenesis in adult humans. Cell. 2013;153(6):1219-27.

70. Aasebo IE, Blankvoort S, Tashiro A. Critical maturational period of new neurons in adult dentate gyrus for their involvement in memory formation. Eur J Neurosci. 2011;33(6):1094-100.

71. Aimone JB, Gage FH. Modeling new neuron function: a history of using computational neuroscience to study adult neurogenesis. Eur J Neurosci. 2011;33(6):1160-9.

72. Aimone JB, Deng W, Gage FH. Resolving new memories: a critical look at the dentate gyrus, adult neurogenesis, and pattern separation. Neuron. 2011;70(4):589-96.

73. Aimone JB, Wiles J, Gage FH. Computational influence of adult neurogenesis on memory encoding. Neuron. 2009;61(2):187-202.

74. Sahay A, Scobie KN, Hill AS, O'Carroll CM, Kheirbek MA, Burghardt NS, et al. Increasing adult hippocampal neurogenesis is sufficient to improve pattern separation. Nature. 2011;472(7344):466-70.

75. Bakker A, Kirwan CB, Miller M, Stark CE. Pattern separation in the human hippocampal CA3 and dentate gyrus. Science. 2008;319(5870):1640-2.

76. Albert MS. Cognitive and neurobiologic markers of early Alzheimer disease. Proc Natl Acad Sci U 


\section{Vittalle - Revista de Ciências da Saúde 29 n. 2 (2017) 57-78}

\section{S A. 1996;93(24):13547-51.}

77. Stone SS, Teixeira CM, Devito LM, Zaslavsky K, Josselyn SA, Lozano AM, et al. Stimulation of entorhinal cortex promotes adult neurogenesis and facilitates spatial memory. $\mathbf{J}$ Neurosci. 2011;31(38):13469-84.

78. Rossi C, Angelucci A, Costantin L, Braschi C, Mazzantini M, Babbini F, et al. Brain-derived neurotrophic factor (BDNF) is required for the enhancement of hippocampal neurogenesis following environmental enrichment. The European journal of neuroscience. 2006;24(7):1850-6.

79. Ge S, Sailor KA, Ming GL, Song H. Synaptic integration and plasticity of new neurons in the adult hippocampus. J Physiol. 2008;586(16):3759-65.

80. Kee N, Teixeira CM, Wang AH, Frankland PW. Imaging activation of adult-generated granule cells in spatial memory. Nat Protoc. 2007;2(12):3033-44.

81. Wolf SA, Melnik A, Kempermann G. Physical exercise increases adult neurogenesis and telomerase activity, and improves behavioral deficits in a mouse model of schizophrenia. Brain, behavior, and immunity. 2011;25(5):971-80.

82. Brandt MD, Maass A, Kempermann G, Storch A. Physical exercise increases Notch activity, proliferation and cell cycle exit of type-3 progenitor cells in adult hippocampal neurogenesis. The European journal of neuroscience. 2010;32(8):1256-64.

83. Kronenberg G, Bick-Sander A, Bunk E, Wolf C, Ehninger D, Kempermann G. Physical exercise prevents age-related decline in precursor cell activity in the mouse dentate gyrus. Neurobiol Aging. 2006;27(10):1505-13.

84. Fabel K, Kempermann G. Physical activity and the regulation of neurogenesis in the adult and aging brain. Neuromolecular Med. 2008;10(2):59-66.

85. Kannangara TS, Lucero MJ, Gil-Mohapel J, Drapala RJ, Simpson JM, Christie BR, et al. Running reduces stress and enhances cell genesis in aged mice. Neurobiol Aging. 2011;32(12):2279-86.

86. Naylor AS, Persson AI, Eriksson PS, Jonsdottir IH, Thorlin T. Extended voluntary running inhibits exercise-induced adult hippocampal progenitor proliferation in the spontaneously hypertensive rat. J Neurophysiol. 2005;93(5):2406-14.

87. Marlatt MW, Potter MC, Bayer TA, van Praag H, Lucassen PJ. Prolonged running, not fluoxetine treatment, increases neurogenesis, but does not alter neuropathology, in the $3 \times \mathrm{Tg}$ mouse model of Alzheimer's disease. Curr Top Behav Neurosci. 2013;15:313-40.

88. Rhodes JS, van Praag H, Jeffrey S, Girard I, Mitchell GS, Garland T, Jr., et al. Exercise increases hippocampal neurogenesis to high levels but does not improve spatial learning in mice bred for increased voluntary wheel running. Behav Neurosci. 2003;117(5):1006-16.

89. Eadie BD, Redila VA, Christie BR. Voluntary exercise alters the cytoarchitecture of the adult dentate gyrus by increasing cellular proliferation, dendritic complexity, and spine density. J Comp Neurol. 2005;486(1):39-47.

90. Redila VA, Christie BR. Exercise-induced changes in dendritic structure and complexity in the adult hippocampal dentate gyrus. Neuroscience. 2006;137(4):1299-307.

91. Kannangara TS, Webber A, Gil-Mohapel J, Christie BR. Stress differentially regulates the effects of voluntary exercise on cell proliferation in the dentate gyrus of mice. Hippocampus. 2009;19(10):889-97.

92. Yau SY, Lau BW, Tong JB, Wong R, Ching YP, Qiu G, et al. Hippocampal neurogenesis and dendritic plasticity support running-improved spatial learning and depression-like behaviour in stressed rats. PLoS One. 2011;6(9):e24263.

93. Patten AR, Sickmann H, Hryciw BN, Kucharsky T, Parton R, Kernick A, et al. Long-term exercise is needed to enhance synaptic plasticity in the hippocampus. Learn Mem. 2013;20(11):642-7.

94. Kerr AL, Swain RA. Rapid cellular genesis and apoptosis: effects of exercise in the adult rat. Behav Neurosci. 2011;125(1):1-9.

95. Bednarczyk MR, Aumont A, Decary S, Bergeron R, Fernandes KJ. Prolonged voluntary wheelrunning stimulates neural precursors in the hippocampus and forebrain of adult CD1 mice. Hippocampus. 2009;19(10):913-27.

96. Bednarczyk MR, Hacker LC, Fortin-Nunez S, Aumont A, Bergeron R, Fernandes KJ. Distinct stages of adult hippocampal neurogenesis are regulated by running and the running environment. Hippocampus. 2011;21(12):1334-47. 


\section{P. N. Castro et al / Vittalle 29 n. 2 (2017) 57-78}

97. Fuss J, Ben Abdallah NM, Vogt MA, Touma C, Pacifici PG, Palme R, et al. Voluntary exercise induces anxiety-like behavior in adult C57BL/6J mice correlating with hippocampal neurogenesis. Hippocampus. 2010;20(3):364-76.

98. Nishijima T, Kawakami M, Kita I. Long-term exercise is a potent trigger for DeltaFosB induction in the hippocampus along the dorso-ventral axis. PLoS One. 2013;8(11):e81245.

99. Biedermann SV, Fuss J, Steinle J, Auer MK, Dormann C, Falfan-Melgoza C, et al. The hippocampus and exercise: histological correlates of MR-detected volume changes. Brain Struct Funct. 2016;221(3):1353-63.

100. Merkley CM, Jian C, Mosa A, Tan YF, Wojtowicz JM. Homeostatic regulation of adult hippocampal neurogenesis in aging rats: long-term effects of early exercise. Front Neurosci. 2014;8:174.

101. Cowansage KK, LeDoux JE, Monfils MH. Brain-derived neurotrophic factor: a dynamic gatekeeper of neural plasticity. Curr Mol Pharmacol. 2010;3(1):12-29.

102. Lipsky RH, Marini AM. Brain-derived neurotrophic factor in neuronal survival and behavior-related plasticity. Ann N Y Acad Sci. 2007;1122:130-43.

103. Neeper SA, Gomez-Pinilla F, Choi J, Cotman C. Exercise and brain neurotrophins. Nature. 1995;373(6510):109.

104. Sartori CR, Vieira AS, Ferrari EM, Langone F, Tongiorgi E, Parada CA. The antidepressive effect of the physical exercise correlates with increased levels of mature BDNF, and proBDNF proteolytic cleavage-related genes, p11 and tPA. Neuroscience. 2011;180:9-18.

105. Liu YF, Chen HI, Wu CL, Kuo YM, Yu L, Huang AM, et al. Differential effects of treadmill running and wheel running on spatial or aversive learning and memory: roles of amygdalar brain-derived neurotrophic factor and synaptotagmin I. J Physiol. 2009;587(Pt 13):3221-31.

106. Hopkins ME, Nitecki R, Bucci DJ. Physical exercise during adolescence versus adulthood: differential effects on object recognition memory and brain-derived neurotrophic factor levels. Neuroscience. 2011;194:84-94.

107. Hopkins ME, Bucci DJ. BDNF expression in perirhinal cortex is associated with exercise-induced improvement in object recognition memory. Neurobiol Learn Mem. 2010;94(2):278-84.

108. Bliss TV, Lomo T. Long-lasting potentiation of synaptic transmission in the dentate area of the anaesthetized rabbit following stimulation of the perforant path. J Physiol. 1973;232(2):331-56.

109. Bruel-Jungerman E, Davis S, Laroche S. Brain plasticity mechanisms and memory: a party of four. Neuroscientist. 2007;13(5):492-505.

110. Titterness AK, Wiebe E, Kwasnica A, Keyes G, Christie BR. Voluntary exercise does not enhance long-term potentiation in the adolescent female dentate gyrus. Neuroscience. 2011;183:25-31.

111. Vasuta C, Caunt C, James R, Samadi S, Schibuk E, Kannangara T, et al. Effects of exercise on NMDA receptor subunit contributions to bidirectional synaptic plasticity in the mouse dentate gyrus. Hippocampus. 2007;17(12):1201-8.

112. O'Callaghan RM, Ohle R, Kelly AM. The effects of forced exercise on hippocampal plasticity in the rat: A comparison of LTP, spatial- and non-spatial learning. Behav Brain Res. 2007;176(2):362-6.

113. Lee CD, Folsom AR, Blair SN. Physical activity and stroke risk: a meta-analysis. Stroke. 2003;34(10):2475-81.

114. Erickson KI, Miller DL, Roecklein KA. The aging hippocampus: interactions between exercise, depression, and BDNF. Neuroscientist. 2012;18(1):82-97.

115. Baker LD, Frank LL, Foster-Schubert K, Green PS, Wilkinson CW, McTiernan A, et al. Effects of aerobic exercise on mild cognitive impairment: a controlled trial. Arch Neurol. 2010;67(1):71-9.

116. Blumenthal JA, Babyak MA, Moore KA, Craighead WE, Herman S, Khatri P, et al. Effects of exercise training on older patients with major depression. Arch Intern Med. 1999;159(19):2349-56.

117. Cotman CW, Berchtold NC. Exercise: a behavioral intervention to enhance brain health and plasticity. Trends Neurosci. 2002;25(6):295-301.

118. Erickson KI, Raji CA, Lopez OL, Becker JT, Rosano C, Newman AB, et al. Physical activity predicts gray matter volume in late adulthood: the Cardiovascular Health Study. Neurology. 2010;75(16):1415-22.

119. Mattson MP. Neuroprotective signaling and the aging brain: take away my food and let me run. 
Brain Res. 2000;886(1-2):47-53.

120. Winter B, Breitenstein C, Mooren FC, Voelker K, Fobker M, Lechtermann A, et al. High impact running improves learning. Neurobiol Learn Mem. 2007;87(4):597-609.

121. Monti JM, Hillman CH, Cohen NJ. Aerobic fitness enhances relational memory in preadolescent children: the FITKids randomized control trial. Hippocampus. 2012;22(9):1876-82.

122. Chaddock L, Erickson KI, Prakash RS, Kim JS, Voss MW, Vanpatter M, et al. A neuroimaging investigation of the association between aerobic fitness, hippocampal volume, and memory performance in preadolescent children. Brain Res. 2010;1358:172-83.

123. Herting MM, Nagel BJ. Aerobic fitness relates to learning on a virtual Morris Water Task and hippocampal volume in adolescents. Behav Brain Res. 2012;233(2):517-25.

124. Stroth S, Hille K, Spitzer M, Reinhardt R. Aerobic endurance exercise benefits memory and affect in young adults. Neuropsychol Rehabil. 2009;19(2):223-43.

125. Christensen H, Korten A, Jorm AF, Henderson AS, Scott R, Mackinnon AJ. Activity levels and cognitive functioning in an elderly community sample. Age Ageing. 1996;25(1):72-80.

126. Hultsch DF, Hammer M, Small BJ. Age differences in cognitive performance in later life: relationships to self-reported health and activity life style. J Gerontol. 1993;48(1):P1-11.

127. Pereira AC, Huddleston DE, Brickman AM, Sosunov AA, Hen R, McKhann GM, et al. An in vivo correlate of exercise-induced neurogenesis in the adult dentate gyrus. Proc Natl Acad Sci U S A. 2007;104(13):5638-43.

128. Voss MW, Erickson KI, Prakash RS, Chaddock L, Kim JS, Alves H, et al. Neurobiological markers of exercise-related brain plasticity in older adults. Brain Behav Immun. 2013;28:90-9.

129. Burdette JH, Laurienti PJ, Espeland MA, Morgan A, Telesford Q, Vechlekar CD, et al. Using network science to evaluate exercise-associated brain changes in older adults. Front Aging Neurosci. 2010;2.

130. Erickson KI, Prakash RS, Voss MW, Chaddock L, Hu L, Morris KS, et al. Aerobic fitness is associated with hippocampal volume in elderly humans. Hippocampus. 2009;19(10):1030-9.

131. Yaffe K, Barnes D, Nevitt M, Lui LY, Covinsky K. A prospective study of physical activity and cognitive decline in elderly women: women who walk. Arch Intern Med. 2001;161(14):1703-8.

132. Colcombe S, Kramer AF. Fitness effects on the cognitive function of older adults: a meta-analytic study. Psychol Sci. 2003;14(2):125-30.

133. Colcombe SJ, Kramer AF, Erickson KI, Scalf P, McAuley E, Cohen NJ, et al. Cardiovascular fitness, cortical plasticity, and aging. Proc Natl Acad Sci U S A. 2004;101(9):3316-21.

134. Smith PJ, Blumenthal JA, Hoffman BM, Cooper H, Strauman TA, Welsh-Bohmer K, et al. Aerobic exercise and neurocognitive performance: a meta-analytic review of randomized controlled trials. Psychosom Med. 2010;72(3):239-52.

135. Barnes DE, Yaffe K, Satariano WA, Tager IB. A longitudinal study of cardiorespiratory fitness and cognitive function in healthy older adults. J Am Geriatr Soc. 2003;51(4):459-65.

136. Kramer AF, Hahn S, Cohen NJ, Banich MT, McAuley E, Harrison CR, et al. Ageing, fitness and neurocognitive function. Nature. 1999;400(6743):418-9.

137. Prakash RS, Voss MW, Erickson KI, Lewis JM, Chaddock L, Malkowski E, et al. Cardiorespiratory fitness and attentional control in the aging brain. Front Hum Neurosci. 2011;4:229.

138. Intlekofer KA, Cotman CW. Exercise counteracts declining hippocampal function in aging and Alzheimer's disease. Neurobiol Dis. 2013;57:47-55.

139. Burdette JH, Laurienti PJ, Espeland MA, Morgan A, Telesford Q, Vechlekar CD, et al. Using network science to evaluate exercise-associated brain changes in older adults. Front Aging Neurosci. 2010;2:23.

140. Erickson KI, Weinstein AM, Lopez OL. Physical activity, brain plasticity, and Alzheimer's disease. Arch Med Res. 2012;43(8):615-21.

141. Marlatt MW, Lucassen PJ, van Praag H. Comparison of neurogenic effects of fluoxetine, duloxetine and running in mice. Brain Res. 2010;1341:93-9.

142. Dostes S, Dubreucq S, Ladeveze E, Marsicano G, Abrous DN, Chaouloff F, et al. Running per se stimulates the dendritic arbor of newborn dentate granule cells in mouse hippocampus in a duration- 
dependent manner. Hippocampus. 2016;26(3):282-8.

143. Bhattacharya TK, Pence BD, Ossyra JM, Gibbons TE, Perez S, McCusker RH, et al. Exercise but not (-)-epigallocatechin-3-gallate or beta-alanine enhances physical fitness, brain plasticity, and behavioral performance in mice. Physiol Behav. 2015;145:29-37.

144. Vivar C, Peterson BD, van Praag H. Running rewires the neuronal network of adult-born dentate granule cells. Neuroimage. 2016;131:29-41.

145. Biedermann S, Fuss J, Zheng L, Sartorius A, Falfan-Melgoza C, Demirakca T, et al. In vivo voxel based morphometry: detection of increased hippocampal volume and decreased glutamate levels in exercising mice. Neuroimage. 2012;61(4):1206-12. 